\title{
RECURSO NATURAL: A CONSTRUÇÃO DE UM CONCEITO
}

\author{
Luis Antonio Bittar Venturi*
}

\section{RESUMO:}

Este texto apresenta os resultados de um processo de discussão ocorrido entre 2005 e 2006 acerca da definição de recurso natural, no qual, a partir de uma idéia simples, foram-se agregando elementos, de modo a resultar em uma definição que, preliminarmente, resolveria alguns dos diversos questionamentos da análise geográfica sobre os recursos naturais. A definição aqui proposta objetiva a retomada da discussão conceitual acerca dos recursos naturais.

\section{PALAVRAS-CHAVE:}

recurso natural - demanda - uso

\section{ABSTRACT:}

This text presents the results of a process of discussion occurred between 2005 and 2006 about the definition of natural resource, in which, starting from a simple idea they were being joined elements, in oder to result in a definition that, previously, they would solve some of the several wonderings of the geographical analysis about the natural resources. The definition here proposed objectifies the retaking of the conceptual discussion about the natural resources.

\section{KEY WORDS:}

natural resource - demand - use

No início do programa da disciplina Geografia dos Recursos Naturais ${ }^{1}$, propõe-se aos alunos que discutam acerca da idéia de recurso natural, ocasião em que podem esboçar as definições que trazem em sua bagagem conceitual. As turmas formadas em 2005 e 2006 totalizaram cerca de duzentos alunos, e a heterogeneidade das classes, característica das disciplinas optativas, refletiu-se em uma interessante diversidade de idéias, a partir da qual delineamos uma discussão que se estendeu por vários meses, paralelamente ao estudo dos recursos naturais. A análise das definições escritas pelos alunos permitiu identificar um núcleo comum de significância a partir do que havia de mais recorrente entre elas, a despeito dos diversos elementos incorporados. Esse núcleo foi expresso na forma de uma simples e breve definição aceita por todos, já que seria necessário haver um consenso inicial para, então, empreendermos a discussão. Assim, partimos da idéia de recurso natural como qualquer elemento da natureza que possa ser explorado pelo Homem. Ainda que essa breve definição resolvesse provisoriamente a questão, e aliviasse a tensão inicial criada pela discussão, ela já se apresentava demasiadamente simples. Portanto, imediatamente após aquele "respirar" inicial, foram surgindo novas questões, tais como: se 
inexistirem as condições para a exploração de um recurso natural, mas houver a demanda por ele, ainda assim será um recurso natural? A definição estaria atrelada ao modo de produção capitalista ou teria um caráter universal? A idéia de recurso natural deveria limitar-se a elementos materiais da natureza? A finalidade da apropriação de um recurso natural pelo Homem deveria estar explícita na definição? Certamente, estas questões relacionam-se aos diversos elementos das definições dos alunos, os quais haviam sido, inicialmente, excluídos do núcleo comum.

Sendo assim, a insatisfação por aquela primeira e breve definição aqueceu as discussões no sentido de se tentar incorporar novos elementos a ela e torná-la mais completa e abrangente. Considerando definição como a explicação de um conceito, poderíamos dizer que qualquer elemento da natureza que possa ser explorado pelo Homem era insuficiente para explicar o conceito de recurso natural e deixava todas aquelas questões em aberto.

A primeira questão a que nos propusemos resolver foi a que se refere à materialidade do recurso natural. O termo elemento remete-nos à idéia de que recurso deve ser algo material e de aproveitamento direto. Diante disso, propôs-se que a definição deveria incluir a imaterialidade de um recurso natural e a possibilidade de a apropriação e uso ocorrerem indiretamente.

O próprio relevo, como um aspecto da paisagem, poderia ser considerado um recurso natural imaterial de aproveitamento indireto. É o caso, por exemplo, do agronegócio em torno do cultivo de soja. Nesse contexto, o aproveitamento direto do solo como recurso natural é viabilizado pelo modelado de relevo aplanado que permite a utilização de maquinário pesado. O relevo, então, estaria sendo indiretamente apropriado. Da mesma forma como as planícies, por sua dinâmica que envolve sedimentação e concentração de umidade, favorecem o desenvolvimento de determinadas culturas, como a do arroz. Poderíamos ainda referir-nos aos represamentos em que a água constitui o recurso natural diretamente apropriado, mas cujo aproveitamento está fortemente condicionado às características do relevo. O aproveitamento energético decorrente de um represamento em área de relevo dissecado seria, certamente, superior àquele em área aplanada, ainda que ambos tivessem a mesma base material; e a diferença em Mega Watts entre os dois empreendimentos seria a forma de materialização do aproveitamento indireto do relevo ${ }^{2}$. No mercado imobiliário, imóveis com o mesmo padrão material podem ter valores diferenciados caso estejam próximos ou voltados para diferentes aspectos da paisagem, como a vista para o mar, por exemplo. A materialização da apropriação indireta deste recurso natural manifesta-se pela diferença de preço dos imóveis. Essa possibilidade existe, já que, culturalmente, alguns aspectos da paisagem são mais valorizados que outros. Por sua vez, o caráter científico e educativo das Unidades de Conservação (UCs), independentemente das materialidades específicas que as compõem, também constitui um tipo de aproveitamento indireto de um recurso natural. O Sistema Nacional de Unidades de Conservação (SNUC) e os planos de manejo, particularmente os dos Parques Nacionais, especificam em seus textos, de forma clara, apropriação indireta dos recursos naturais pelo uso público que essas UCs prevêem, seja de caráter educativo, científico ou recreacional. Em todos esses exemplos, há uma apropriação de determinados aspectos da natureza seja sem que se extraia algum elemento para transformação e uso.

A paisagem pode ser também compreendida como um aspecto do mundo real que tem valor por si mesmo, já que pode oferecer satisfação estética, recreacional, espiritual, ou ainda ser objeto para fins educacionais e científicos. Nem por isso a paisagem restringe-se a um resultado visual que nos chega aos olhos. Referimo-nos aqui a uma categoria geográfica, compreendida como uma resultante da interação entre componentes físicos, biológicos e sociais, cuja dinâmica evolutiva 
envolve, portanto, matérias, energias e valores.

Muitos autores trabalharam na definição de paisagem e esta discussão poderia ainda ser ilustrada com mais exemplos ${ }^{3}$. Mas retomemos a questão da imaterialidade que, a esta altura, tinha a sua inclusão na definição de recurso natural como uma decisão unânime. Isso foi resolvido acrescentando, simplesmente, o termo aspecto à definição inicial: qualquer elemento ou aspecto da natureza... Incorporando esta idéia, surgiu a necessidade de explicitar a possibilidade de aproveitamento indireto relacionado ao aspecto, além do direto relacionado ao elemento. Isto pôde ser resolvido incluindo, entre vírgulas, as palavras direta ou indiretamente, no enunciado.

Partimos, então, para um segundo questionamento: aquela primeira definição de recurso natural desvincula-o de contextos históricos. No entanto, algum bem natural pode ser recurso natural em determinado contexto histórico e deixar de sê-lo em outro. Ou ainda, algo que nunca se constituiu em um recurso natural pode vir a sê-lo, de acordo com um novo contexto, dependendo dos diferentes níveis de desenvolvimento tecnológico, assim como dos diferentes conjuntos de valores culturais assimilados por determinada sociedade em certo tempo e espaço. Além disso, deve-se evitar confundir elemento natural com recurso natural. Para MENDONÇA (2001),

Os elementos da natureza não devem ser reduzidos somente a recursos, pois, antes de assim transformados, constituem-se em bens e elementos naturais que possuem dinâmica própria e que independentemente de sua apropriação social. (p.127)

Convencidos da necessidade da contextualização do recurso natural, apoiamonos na afirmação de ZIMMERMANN (1966): "Os recursos não são: eles se tornam". Assim, a idéia da demanda seria fundamental para historicizar a definição de recurso natural. Então, para que um elemento ou um aspecto da natureza, seja considerado um recurso, é preciso que esteja em uso ou que, pelo menos, exista demanda por ele. Além de contextualizar historicamente o recurso natural, a incorporação do termo demanda traz a idéia de que o acesso a ele depende de outros fatores, além de sua ocorrência e distribuição na natureza, como questões técnicas, econômicas ou geopolíticas. Isto significa dizer que o fato de um elemento ou aspecto da natureza estar em demanda torna-o um recurso natural, mas sua apropriação e uso ainda permanecem sem garantias. GODARD (2002) reforça a idéia de historicidade do conceito quando diz que

[...] os recursos não podem ser fixados de uma vez por todas; o conteúdo daquilo que denominamos recursos transforma-se historicamente e depende tanto da evolução dos ambientes quanto da evolução das possibilidades técnicas, da natureza das necessidades sociais e das condições econômicas. (p.207)

Assim, a definição inicial de recurso natural incorporou essa idéia e passou a ter, provisoriamente, o seguinte enunciado: qualquer elemento ou aspecto da natureza que possa ser explorado pelo Homem, direta ou indiretamente, ou que esteja em demanda. Em verdade, a etimologia do termo recurso já traz, implicitamente, a idéia de algo que está em demanda, pois em uma de suas acepções, no léxico da Língua Portuguesa, o termo é designado como algo a que se recorre (CUNHA, 1982). Ora, o Homem recorre àquilo de que necessita, em um determinado momento histórico. Contudo, se uma definição mantém elementos implícitos em seu enunciado, pode correr o risco de descumprir seu papel: o da explicação de um conceito.

No decorrer das discussões, o termo explorado usado na definição inicial foi questionado a ponto de ser substituído. A exploração de um recurso natural representa os meios que irão possibilitar seu uso. O fim, portanto, é o uso. O recurso natural é, em última instância, algo da natureza que será usado, ainda que, para isso, tenha que ser explorado. Além disso, no universo dos recursos naturais 
minerais, o termo explorar é mais utilizado na acepção de percorrer estudando, procurando do que naquela que designa tirar partido abusivamente de algo, mais utilizada pelas ciências sociais. O termo mais adequado para designar que algo está sendo extraído da natureza seria explotar, que significa tirar proveito (econômico) de uma área, principalmente quanto aos recursos naturais ${ }^{4}$. De qualquer forma, ambos os termos referem-se aos meios, e, portanto, adotamos, em substituição, o termo utilizado, que se refere ao fim.

Um outro questionamento proposto referia-se à finalidade dos recursos naturais. Seu uso estaria vinculado apenas às necessidades materiais do Homem, ou, também, a seus anseios, desejos, ou carências? Observou-se que a idéia de recurso natural tem sido concebida fortemente ligada às necessidades humanas, justamente por estar relacionada à idéia de materialidade, à recorrência a um valor material proveniente da natureza.

Porém, os valores estéticos e educacionais da paisagem representam, ao serem apropriados, a busca da satisfação de outras necessidades, além das físico-materiais relacionadas à sobrevivência do Homem. Relacionam-se às carências, aos desejos, aos anseios e, portanto, ao conjunto de valores culturais socialmente assimilados em um determinado tempo e espaço. Considerando que o que diferencia o Homem dos outros animais é mais do que seu pensamento teleológico que transforma a natureza pelo trabalho; é mais do que apenas a sua razão, mas também a criação de um universo simbólico que se interpõe na sua relação com o mundo, a idéia de recurso natural deveria transcender o significado marxista de objeto e meio de trabalho voltado à satisfação das necessidades humanas. Se a vista para o mar representa a apropriação indireta de um recurso natural representado por um aspecto da paisagem, esta apropriação refere-se a um anseio, um desejo relacionado a valores culturais, mais do que à satisfação de necessidades ${ }^{5}$. Muito se discutiu em sala de aula sobre qual seria o termo mais adequado para incorporar esta idéia à definição de recurso natural que estávamos tentando construir. Pensou-se em anseios, carências, desejos... mas, ao final, havia o risco de criarmos neologismos ou utilizarmos, indevidamente, conceitos da psicologia. Decidiuse, assim, por um enunciado simples e direto que se referia às necessidades físicas e culturais, contemplando, na definição, deste modo, as finalidades de uso dos recursos naturais. Como a definição já se constitui como uma explicação, ela deveria evitar incorporar termos que poderiam requerer novas explicações. Neste sentido, a clareza, a simplicidade e a precisão qualificariam o enunciado da definição. Por esta razão, mantivemos o termo natureza, no lugar de paisagem. Ainda que natureza possa, também, representar uma categoria, sobretudo na Filosofia, a paisagem, na qualidade de categoria geográfica, poderia requerer novas explicações e, no lugar de uma definição ampla, geraríamos uma discussão conceitual, de certa forma, circunscrita aos geógrafos. Este fato poderia conduzir a um desvio do objetivo inicialmente proposto: o de tentar construir uma definição de recurso natural que, embora dentro de uma perspectiva geográfica, pudesse, também, ser assimilada por outras áreas do conhecimento.

A inclusão das necessidades culturais poderia, inclusive, ajudar a resolver o caráter econômico da apropriação dos recursos naturais, já que produtividade e lucro poderiam incluir-se dentro do conjunto de valores assimilados pela sociedade em determinado contexto. E a inclusão da idéia de necessidade cultural foi favorecida pela incorporação do termo aspecto que já havia sido feita à definição, ainda que inexista uma relação de exclusividade entre elementos e necessidades, e entre aspectos e anseios. Um elemento material pode ser apropriado para satisfazer um desejo. Do mesmo modo, um aspecto pode ser apropriado para resolver uma necessidade material (o exemplo do relevo nos represamentos).

Isto posto, podemos afirmar que seria 
impossível conceber recurso natural apenas pela perspectiva da natureza ou apenas pela perspectiva social. O recurso natural, por estar ligado às necessidades físicas e culturais do Homem, por representar um olhar do Homem sobre a natureza, exige uma abordagem física e humana, ou seja, uma abordagem geográfica como a concebemos. Para GODARD (op cit),

Recurso Natural é um conceito situado na interface entre processos sociais e processos naturais: ele resulta do olhar lançado pelos homens sobre seu meio biofísico, um olhar orientado por suas necessidades, seus conhecimentos e seu savoir-faire.(p.205)

Em seguida, questionou-se se a idéia de recurso natural deveria estar exclusivamente vinculada ao modo de produção capitalista. Ainda que haja uma estreita relação entre apropriação de recursos naturais e reprodução de qualquer modo de produção, inclusive capitalista, ela Ihe seria exclusiva? Isto ocorreria caso a idéia do trabalho como forma de apropriação do recurso natural sobreponha-se à idéia do recurso natural em si, como algo a que se recorre. Neste caso, poderíamos pensar que recurso natural estaria fortemente vinculado ao trabalho como reprodução do sistema capitalista. Para LEFF (2001),

O recurso natural e a força de trabalho não são entes naturais existentes independentemente do social, mas são já o biológico determinado pelas condições de produção e reprodução de uma dada estrutura social. (p.121)

Mas, ao compreendermos recurso natural como algo a que se recorre, independentemente dos meios de apropriação e uso, ele poderia ser concebido como tal em outros modos de produção: primitivos, orientais, feudais ou mesmo socialistas. O Homem, ao perceber a natureza como algo que pode, de alguma forma, ser aproveitado, transforma o elemento natural em recurso natural. Isso pode ocorrer independentemente do advento do capitalismo, e pode, inclusive, existir em meio às sociedades indígenas, ainda que nessas últimas inexista trabalho na forma como é concebido no sistema capitalista. A afirmação de MORAES e COSTA (1999) de que o espaço pode "possuir um valor intrínseco, não necessariamente produto do trabalho humano, uma riqueza natural" (p. 124) poderia corroborar a idéia proposta se interpretarmos riqueza natural como recurso natural. De todas as maneiras, parece estar implicitamente presente a idéia de recurso como a algo que se recorre para um determinado uso: seja para a reprodução do capital, para garantir a sobrevivência, a reprodução de valores culturais e religiosos ${ }^{6}$, para a satisfação de necessidades ou anseios, vinculados ou não às leis de mercado.

A incorporação dessa idéia exigiu novas alterações à definição inicial. Propôs-se em qualquer tempo ou espaço ou em determinado tempo ou espaço para atribuir maior abrangência à definição de recurso natural. De uma forma ou de outra, a questão da demanda já estaria, implicitamente, relacionando o recurso natural a um determinado contexto histórico, como vimos.

Mais alguns ajustes no enunciado da definição também foram sugeridos: considerouse mais adequada a expressão passível de ser utilizado, já que a existência de um recurso representaria apenas uma possibilidade de apropriação e uso. Esta expressão atribui-lhe um caráter mais provisório, exigido pela contextualização.

Chegamos, assim, a um enunciado de uma definição cujo texto parecia alinhavar todas aquelas idéias, portanto, dentro de uma perspectiva geográfica, um potencial explicativo bem mais satisfatório do que aquela primeira breve definição inicial:

Recurso natural pode ser definido como qualquer elemento ou aspecto da natureza que esteja em demanda, seja passível de uso ou esteja sendo usado pelo Homem, direta ou indiretamente, como forma de satisfação de suas necessidades físicas e culturais em determinado tempo e espaço. 
Um recurso natural poderia, ainda, ser classificado em várias categorias, como recursos renováveis, não renováveis, esgotáveis, reprodutíveis, entre outros desdobramentos que poderiam alimentar novas discussões. Obviamente que alguns importantes aspectos deixaram de ser contemplados ou o foram de forma insatisfatória até este momento. A incorporação de mais autores à discussão; a forma como recurso natural e bem natural são tratados na legislação; uma maior confrontação entre diferentes definições; um estudo etimológico mais aprofundado dos termos utilizados; a evolução do conceito de recurso natural e seu uso em diferentes contextos históricos; tudo isso poderia enriquecer as discussões atribuindo-lhes um embasamento teórico-conceitual mais sólido. Mas o processo não se havia encerrado e essa discussão conceitual foi retomada em 2006. Novos questionamentos surgiram e novos elementos foram incorporados à definição de recurso natural que havíamos elaborado ${ }^{7}$.

Durante o transcorrer da referida disciplina, em 2006, os alunos tiveram contato em campo com alguns recursos naturais, como caulim, minério de ferro, petróleo, entre outros. Surgiu, então, a seguinte dúvida: até que grau de beneficiamento e transformação um elemento pode ainda ser considerado natural? Em outras palavras, o caulim, após sofrer beneficiamento para purificação e branqueamento, poderia ainda ser considerado um recurso natural? O minério de ferro, após passar por beneficiamento para transformação dos materiais finos em pelotas, deixaria de ser um recurso natural na medida em que na natureza não ocorrem estruturas pelotizadas deste mineral? Ou poderia ainda ser assim considerado, uma vez que a materialidade do ferro in natura e a das pelotas é a mesma, diferentemente da transformação do ferro em gusa ou aço, que já são produtos derivados? Se, por um lado, o ferro gusa e o aço, definitivamente, não são recursos naturais pois não ocorrem na natureza, mas são produtos da transformação de elementos naturais, por outro, argilo-minerais, como o caulim, podem ocorrer de forma pura e naturalmente selecionados (argilas de sedimentação) sem passar por processos de beneficiamento. Se a gasolina não é um recurso natural como o petróleo o é, como se classificaria o óleo combustível como subproduto primário do processo de refinamento?

Em relação ao recurso como um aspecto da natureza, um parque que tenha sofrido importante intervenção paisagística ainda seria um recurso natural de aproveitamento indireto? Em meio a essas dúvidas, concluímos, então, que existe um limite impreciso entre o que pode ser considerado recurso natural e o que deixa de sê-lo por ter sofrido importante transformação pelo trabalho humano. Se não conseguimos precisar esse limite, pelo menos chamamos a atenção para ele, acrescentando essa idéia à definição anterior da seguinte maneira: (...) os recursos naturais são componentes da paisagem geográfica, materiais ou não, que ainda não sofreram importantes transformações pelo trabalho humano e cuja própria gênese independe do Homem (...). Apesar de a ocorrência e distribuição dos recursos naturais depender de dinâmicas naturais, como já foi visto, eles só podem assim ser considerados segundo uma perspectiva histórica, portanto, só podem ser compreendidos a partir de uma perspectiva geográfica que relaciona a sociedade e a natureza. Essa relação representaria um importante fator explicativo dos diferentes níveis de organização social sobre o território, que se produz na intersecção entre valores sociais e dinâmicas naturais.

Ao discutirmos o conceito de valor local, um outro aspecto foi trazido à discussão: um recurso de alto valor local é aquele que apresenta baixo valor de troca, alto valor de uso, envolve grandes quantidades e é, geralmente, insubstituível, a exemplo das matérias brutas (areia e brita) para construção civil. Assim, a despeito da ocorrência do recurso no estrato geográfico, ele terá maior ou menor mobilidade sobre o território exercendo forte influência em sua configuração, dependendo de seu valor local. Se a areia é geograficamente 
engessada, os minerais metálicos ou energéticos não o são, podendo ser transportados e comercializados em qualquer parte do mundo, a exemplo do petróleo, do alumínio, ouro, entre outros. Incorporou-se esta idéia acrescentando-se à definição a frase: (...) sendo que quanto mais valorizado é um recurso, maior sua mobilidade sobre o território.

Ao introduzirmos a discussão sobre o conceito de impacto e suas variações, consideramos que os impactos variam de acordo com a natureza do recurso, sua forma de ocorrência, a forma de apropriação e uso a ele atribuído. Assim, os impactos podem ser locais, regionais, irreversíveis, sazonais, sociais, estratégicos, positivos, negativos, entre tantas variações. O único elemento comum que poderia ser incorporado à definição de recurso natural é a idéia de que sempre haverá alguma transformação no ambiente e na sociedade, seja na exploração, apropriação, transformação ou no uso dos recursos naturais. Nesse processo, tais alterações seriam tanto menos negativas quanto mais se considerarem, ao mesmo tempo, a dinâmica natural que envolve o recurso, como aspectos éticos em sua apropriação e uso. No enunciado, essa idéia foi assim descrita:

(...) De qualquer forma, sempre haverá alguma alteração no ambiente, seja na exploração, apropriação ou no uso dos recursos naturais. Tais alterações podem tornar-se negativamente impactantes se a apropriação dos recursos desconsiderar as dinâmicas naturais, e/ou orientar-se por procedimentos não éticos ${ }^{8}$.

A atenção a alguns fatos relacionados a recursos naturais ocorridos no contexto do semestre, a exemplo da crise do gás da Bolívia e da pressão sobre o Irã em relação ao beneficiamento de urânio, trouxe à discussão um outro elemento: a despeito da ocorrência natural, da demanda, das técnicas para apropriação e uso e de aspectos mercadológicos, a apropriação e uso dos recursos naturais pode ainda depender de fatores geopolíticos, que podem favorecer ou impossibilitar o acesso a eles. De forma a incorporar esta idéia e contextualizar a definição, acrescentamos que

(...) Além da demanda, da ocorrência e de meios técnicos, a apropriação e uso dos recursos naturais pode depender também de questões geopolíticas, sobretudo quando se caracterizam como estratégicos, envolvendo disputa entre povos.

Finalmente, ao analisarmos comparativamente, no decorrer do curso, algumas nações ricas em recursos naturais e seus respectivos IDHs (Índice de Desenvolvimento Humano) e PIBs (Produto Interno Bruto), torna-se clara a impossibilidade de se relacionar diretamente recursos naturais com desenvolvimento. Nações que apresentam exíguas reservas de recursos naturais podem apresentar índices de desenvolvimento muito altos (a exemplo do Japão); por outro lado, no Brasil, onde há grande disponibilidade de praticamente todos os recursos demandados pelo mundo contemporâneo, não se verifica uma reversão correspondente dessa riqueza em benefício social, fato que atribui especial importância às questões políticas e econômicas no estudo dos recursos naturais.

Buscando incorporar todos essas questões levantadas no processo coletivo de discussão, alinhavamos uma definição de recurso natural cuja versão apresenta-se mais complexa e detalhada:

Recurso natural pode ser definido como qualquer elemento ou aspecto da natureza que esteja em demanda, seja passível de uso ou esteja sendo usado direta ou indiretamente pelo Homem como forma de satisfação de suas necessidades físicas e culturais, em determinado tempo e espaço. Os recursos naturais são componentes da paisagem geográfica, materiais ou não, que ainda não sofreram importantes transformações pelo trabalho humano e cuja própria gênese independe do Homem, mas aos quais foram 
atribuídos, historicamente, valores econômicos, sociais e culturais. Portanto, só podem ser compreendidos a partir da relação Homem-Natureza. Se, por um lado, os recursos naturais ocorrem e distribuem-se no estrato geográfico segundo uma combinação de processos naturais, por outro, sua apropriação ocorre segundo valores sociais. Dessa interação sociedade-natureza decorrem determinadas formas de organização social sobre o território, influenciadas, tanto pelos processos naturais que determinam a ocorrência (ou a não ocorrência) e a distribuição territorial dos recursos, como pelos valores sociais vigentes no contexto da apropriação, sendo que quanto mais valorizado é um recurso, maior sua mobilidade sobre o território. De qualquer forma, sempre haverá alguma alteração no ambiente, seja na exploração, apropriação ou no uso dos recursos naturais. Tais alterações podem tornar-se negativamente impactantes se a apropriação dos recursos desconsiderar as dinâmicas naturais, e/ou orientar-se por procedimentos não éticos. Além da demanda, da ocorrência e de meios técnicos, a apropriação e uso dos recursos naturais podem depender, também, de questões geopolíticas, sobretudo, quando se caracterizam como estratégicas, envolvendo disputas entre povos. Se, por um lado, as dinâmicas naturais explicam a riqueza de recursos naturais que algumas nações apresentam, as dinâmicas sociais podem explicar a não correspondência direta entre disponibilidade de recursos naturais e bem estar e desenvolvimento humano.

Este seria, então, o resultado de vários meses de discussões envolvendo um grande número de alunos. As duas versões da definição de recurso natural, uma mais sucinta e objetiva e outra mais detalhada, não são excludentes nem, tampouco, encerram o processo de construção conceitual. No entanto, esperamos, com estas definições, reacender a discussão acerca dos recursos naturais e contribuir para a construção de um conceito que transcenda a perspectiva puramente econômica ou natural e alcance uma perspectiva mais geográfica, mais universal.

\section{Notas}

${ }^{1}$ Disciplina optativa oferecida no curso de Geografia (FFLCH-USP).

${ }^{2}$ A esse respeito ver VENTURI (2001).

3 Para Carlos Augusto de Figueiredo Monteiro, por exemplo, a paisagem é entendida como uma "Entidade espacial delimitada segundo um nível de resolução do geógrafo (pesquisador) a partir dos objetivos centrais da análise, de qualquer modo, sempre resultante da integração dinâmica, portanto instável, dos elementos de suporte e cobertura (físicos, biológicos e antrópicos) expressa em partes delimitáveis infinitamente mas individualizadas através das relações entre elas que organizam um todo complexo (Sistema), verdadeiro conjunto solidário e único, em perpétua evolução". (MONTEIRO, 2000, p.39) Grifo nosso.
${ }^{4}$ Novo Dicionário Aurélio. Rio de Janeiro: Nova Fronteira, s/d, p.600.

5 MORAES e COSTA (1999) afirmam que "A valorização do espaço passa necessariamente pelas formas de pensamento que os homens constroem na sua relação com seu espaço" (p.146), enfatizando a questão da subjetividade.

${ }^{6}$ A exemplo do significado religioso do rio Ganges, na Índia.

7 Agradeço aos professores Carlos Augusto de Figueiredo Monteiro e Francisco de Assis Mendonça, os quais, por e-mail, enviaram da França valiosas críticas e sugestões à primeira versão deste texto.

${ }^{8}$ Ética aqui entendida simplesmente como atributo da ação que se volta para o bem comum. 


\section{Bibliografia}

AB'SABER, A. N. (2003) Os domínios de natureza no Brasil. São Paulo: Atelier Editorial.

CUNHA, A. G. (1982) Dicionário Etimológico Nova Fronteira da Língua Portuguesa. 2. ed. Rio de Janeiro: Nova Fronteira.

GODARD, O. (2002) Gestão integrada dos recursos naturais e do meio ambiente: conceitos, instituições e desafios de legitimação. In: VIEIRA, P.F. \& WEBER, J. (org.) Gestão de recursos naturais renováveis e desenvolvimento. São Paulo: Cortez. 500p.

LEFF, H. (2001) Epistemologia ambiental. São Paulo: Cortez.

MENDONÇA, F. A. (2001) Geografia socioambiental Revista Terra Livre, n.16. São Paulo: p.113-132.

MONTEIRO, C. A. F. (2000) Geossistema: a história de uma procura. São Paulo: Ed. Contexto. (Coleção Novas Abordagens,3)

MORAES, A.C.R. \& COSTA, W.M. (1999) Geografia crítica: a valorização do espaço. 4. ed. São Paulo: Hucitec.

VENTURI, L. A. B. (2001) O relevo como recurso imaterial. Revista Unifieo, n.6. São Paulo: Edifieo. P. 144-147.

ZIMMERMANN, E.W. (1966) Introducción a los recursos mundiales. Barcelona: Oikos-Tau. 
